\title{
Modern Ophelialar: Karşılaştırmalı edebiyat bilimi çerçevesinde bir uygulama
}

\section{Senem ÜSTÜN KAYA1}

\begin{abstract}
APA: Üstün Kaya, S. (2020). Modern ophelialar: Karşılaştırmalı edebiyat bilimi çerçevesinde bir uygulama. RumeliDE Dil ve Edebiyat Araştırmaları Dergisi, (18), 170-178. DOI: 10.29000/rumelide.705567.
\end{abstract}

\section{Özet}

Karşılaştırmalı edebiyat bilimi, farklı dillerde ve ya farklı dönemlerde yazılmış edebi eserlerin, imgeler, konular, tipler, biçem ve ya içerik açısından mukayese edildiği edebiyat alanıdır (Aytaç 2001). Farklı kültürlere ait olsalar da, evrensel sosyal, politik ve ekonomik konular sebebiyle, birçok edebi eser, başka milletlerin eserlerini anıştırabilir, çağrıştırabilir ve ya yansıtabilir. Yüzyıllardır, sayısız edebi eserde, değişmeyen ve yinelenen önemli konulardan biri de, ataerkil toplumlarda kendilerine dayatılan roller ve sorumlulukların ağırlığı altında ezilen kadınların 'varoluş' savaşıdır. $\mathrm{Bu}$ toplumsal yaranın en etkileyici yansımasını, 17. yüzyılda, William Shakespeare, Hamlet oyunundaki unutulmaz Ophelia karakteri ile vermiştir. Ophelia’yı çağrıştıran, öz benliğini kaybetmiş ve ataerkil toplumda kimlik mücadelesi veren kadınlar, farklı kültürlerin edebiyatlarında yeniden betimlenmiştir. Bu çalışmanın amacı, Ophelia karakterinin, yüzyıllar sonra dünya edebiyatlarına nasıl yansıdığını göstermek adına farklı edebi eserlerden seçilmiş kadın karakterleri incelemektir. Bu bağlamda, Doris Lessing’in 'Ondokuz Numaralı Oda' (1963) hikâyesindeki Susan Rawlings ve Halide Edip Adıvar'ın Handan (1912) romanındaki Handan karakterleri karşılaştırmalı olarak incelenmiştir.

Anahtar kelimeler: Karşılaştırmalı edebiyat bilimi, varoluş, öz benlik, 'Ondokuz Numaralı Oda', Handan, Hamlet.

\section{A practice on science of comparative literature: Modern Ophelias}

\begin{abstract}
The Science of comparative literature is a literary branch which involves the comparison of literary texts, written in different languages or in different periods, in terms of images, themes, characters, style or content (Aytaç, 2001). Many literary texts of different cultures might hint, recall or mirror the other nations' literature due to universal social, political and economic issues. For centuries, one of the significant unchanging and repeated themes is the struggle of 'existence' of women, who have been overwhelmed by the imposed roles and responsibilities in patriarchal societies. In the 17th century, William Shakespeare presented the most effective reflection of this social problem with his memorable character Ophelia in Hamlet. Recalling Ophelia, women, who have lost their identity and struggled for self-identity in patriarchal societies, have been reportrayed in literature of distinctive cultures. The aim of this study is to analyze women characters, chosen from different literary texts, in order to show how Ophelia mirrors in world literature. Within this scope, Doris Lessing's Susan Rawlings in ‘To Room Nineteen’ (1963) and Handan in Halide Edip Adivar's novel Handan (1912) were comparatively analyzed.
\end{abstract}

1 Dr. Öğr. Üyesi, Başkent Üniversitesi, Eğitim Fakültesi, Yabancı Diller Eğitimi Bölümü, İngiliz Dili Eğitimi ABD (Ankara, Türkiye), efesenem@yahoo.com, ORCID ID: 0ooo-0001-6537-9769 [Makale kaylt tarihi: 26.12.2019-kabul tarihi: 20.03.2020; DOI: 10.2900o/rumelide.705567] 
Keywords: Science of comparative literature, existence, self-identity, ‘To Room Nineteen', Handan, Hamlet.

\section{Giriş}

Karşılaştırmalı edebiyat bilimi, farklı dillerde ve ya farklı dönemlerde yazılmış edebi eserlerin, imgeler, konular, tipler, biçem ve ya içerik açısından mukayese edildiği ve yorumlandığı edebiyat alanıdır (Aytaç 2001). 19. yüzyılda doğan karşılaştırmalı edebiyatın en önemli amacı, ulusal edebiyatı dünya edebiyatlarına tanıtmak ve okuyucuya eleştirel bir bakış açısı kazandırmaktır. Bu bağlamda, ulusal bir edebi eseri, farklı kültüre ait bir eserle karşılaştırmak mukayeseli edebiyatın kapsamındadır (Aytaç 2001). Çoğu edebi eserin, öncül eserlerden ve ya aynı döneme ait başka bir dilde yazılmış edebi eserden izler taşıması, okuyucunun metinler arasında karşılaştırma yeteneğini güçlendirir ve mukayeseli edebiyat çalışmalarına zenginlik katar. Bu bağlamda, Karşılaştırmalı edebiyat;

analoji, akrabalık ve etkileşim bağlarının araştırılması suretiyle, edebiyatı diğer ifade ve bilgi alanlarına ya da zaman ve mekân içerisinde birbirine uzak veya yakın durumdaki olaylarla edebî metinleri birbirine yaklaştırmayı amaçlayan yöntemsel bir sanattır. Yeter ki bu edebî metinler, birçok dile ya da kültüre ait olsunlar; onları daha iyi tanımlayıp anlamak ve onlardan zevk alabilmek için aynı geleneğe ait bulunsunlar (Rousseau ve Pichois 1994: 182).

Dünya edebiyatlarında, farklı kültürlerde, ortak bazı sosyal, politik ve ekonomik konuları ele alan eserler, birbirini anıştırır, çağrıştırır ve ya yansıtır. Böylece, dünyadaki olayların eleştirel bir bakış açısı ile yorumlanmasında karşılaştırmalı çalışmalar etkin bir araç olur (Aydın 2008: 53). Değişmeyen evrensel konulardan biri de ataerkil toplumlarda kadının eşitlik ve benlik arayışıdır. Ataerkil toplumlarda tarih boyunca içeri ortamlarda (evlerde) "hapsolan" kadınlar, iyi bir eş, fedakâr anne ve ya itaatkâr kız çocuk rolleri sebebiyle sosyal hayattan uzakta kalmışlardır. Yüzyıllardır, genç kızlara yüklenen tek görev olan "evlilik" uğruna kadınlar, toplumun kabul ettiği birey olmak için kişiliklerinden vazgeçmiş, özerkliklerini kaybetmiş ve "öteki varlık” olmuşlardır (De Beauvoir 1971: 341).

Kadın hareketlerinin başlaması ile eşit hak ve gerçek kimlik arayışında olan çoğu kadın, isyanları sonucu, toplum tarafindan dışlanmış ve soyutlanmışlardır. "Normal" algısına uymayan bu aktif, düşünen, sorgulayan ve isyan eden kadınların kaderleri, edebi metinlerde benzer şekillerde çizilmiştir: deli olarak akıl hastanelerine yatırılmak, duygusal çöküş, zihinsel aksaklıklar, toplumdan soyutlanmak ve ya intihar. Bu bağlamda, toplumsal bir yara olan kadının "kimlik" arayışı, hemen hemen her kültürde edebi eserlere uygun bir konu olmuştur.

$\mathrm{Bu}$ makalenin amacı, farklı kültürlerde farklı yüzyllarda ele alınmış olmasına rağmen ataerkil toplumlarda kadının değişmeyen yeri ve benlik mücadelesini örneklerle göstermektir. Bu bağlamda, William Shakespeare'in Hamlet oyunundaki Ophelia karakterini çağrıştıran ve Türk ve Batı edebiyatlarında önemli etkisi olan iki kadın karakter seçilmiştir: Doris Lessing'in "Ondokuz Numaralı Oda" (“To Room Nineteen”) (1963) adlı kısa hikâyesindeki Susan ve Halide Edip Adıvar'ın Handan (1912) romanındaki Handan.

\section{Metinlerin karşılaştırılması}

William Shakespeare'ın tiyatro eseri Hamlet, babasının intikamını almak adına savaşan bir prensin hikayesi olsa da, arka planda, hayatı boyunca etrafındaki erkeklerin ona biçtiği rolleri oynamak zorunda kalan genç ve uysal Ophelia’nın trajedisi vardır. Ophelia, Hamlet’e olan karşılıksız aşkı ve ailesinin 
baskısı sonucu delirir ve oyunun sonunda intihar eder. Ophelia'nın delirmesinde ve intiharında en büyük sebep hayatındaki erkeklerdir.

Oyunun başında, ilgili bir baba olarak karşımıza çıan Polonius'un Ophelia'ya en önemli nasihati 'iffet' üzerinedir. Ophelia ve Hamlet’in yakınlaşmasından rahatsız olan Polonius kızını uyarır:

Benim de duyduğuma göre son zamanlarda

Pek sık görüşüyormuş seninle.

Sen de bir hayli serbest,

Bir hayli cömert karşıllyormuşsun kendisini.

Şunu bildirmeliyim ki sana,

Pek açık görüyor gibi değilsin

Benim kızıma ve kızımın şerefine yakışanı (s. 34)

Ancak, oyunun üçüncü perdesinde, aynı baba, Claudius'a yaranmak için Hamlet'in delirmesinin sebebinin Ophelia’ya duyduğu aşktan kaynaklandı̆̆ını söyleyerek kızını kendi çıkarları için maşa olarak kullanmaktan çekinmez. Polonius gibi, Ophelia'nın abisi Laertes’in tek derdi güç savaşıdır ve bu uğurda kız kardeşinin duygularını önemsemez ve Hamlet'in Ophelia'ya ilgisini "bir oyun, bir gençlik hevesi” (s. 31) olarak tanımlanır.

Hamlet’in yarattığı çelişkiler Ophelia için daha ağırdır. Sevdiği erkek, babasından dolayı Ophelia'dan uzaklaşmış ve "manastıra" (s. 94) gitmesini söylemiştir. Orijinal metinde "nunnery" olarak geçen kelimenin manastır anlamının dışında genelev anlamı da vardır (akt. Birikiye 2018: 94) ve Hamlet’in bu "gaddarlığı" (Carlisle 1967: 130), Ophelia için delilik ile sonuçlanan duygusal sarsıntının başlangıcıdır. Sevdiği adam babasını öldürmüş ve sürgüne yollanmıştır. Tutunacak dalı kalmayan ve tüm rollerini (kız çocuk, kız kardeş ve ya eş) kaybeden Ophelia, "aidiyet" arayışı içinde, aklını yitirir ve oyunun sonuna doğru intihar eder. Etrafındaki erkeklerin tutarsızlığı, onu kullanmaları ve onları arka arkaya kaybetmenin acısı Ophelia'da duygusal ve "zihinsel çöküntü” (Tüzün 2017: 209) yaratır ve aslında onun intiharı, içinde bulunduğu sisteme tepki ve ya sessiz bir çı̆̆llk olarak kabul edilir.

Yüzyıllar sonra bile edebi eserlerde, mutsuz, çaresiz ve erkeklerin yarattığı normlarla çatışan kadınlar, Ophelia'dan farklı bir son yaşamazlar. Modernleşme akımı ile kadının kimliği ve toplumdaki yeri değişmiştir, ancak, kamusal alanda aktif, eğitimli ve kültürlü kadınlar, geleneksel rolleri ve modern duruşları arasında kalmış ve benlik savaşı vermişlerdir.

Doris Lessing (1919-2013), "Ondokuz Numaralı Oda" (1963) başlıklı hikâyesinde, evli ve dört çocuklu bir kadının, Ophelia gibi yaşadığı kimlik bunalımı sonucu delirişini ve intiharını anlatır. Lessing, Susan'ın yaşamını "zekânın boşa çıkmasına ilişkin bir hikâye” (s. 473) olarak tanımlar. Eğitimli ve sosyal hayatta etkin olan Susan, evlendikten sonra, reklam şirketindeki işini bırakır ve kendini ailesine adar. Çocuklarının büyüyüp okula başlaması ile evde yalnız kalan Susan, hayatı, evliliğini, geçmişini ve benliğini sorgulamaya başlar. Yüzyllardır, ataerkil toplumlarda, üreticilik erkelerle özdeşleşirken, kadınlar yuva ve aile ile bağdaştırılmıştır. Kadınlar, evlendiklerinde hayatlarını eşlerine ve ailelerine adar, yaşamlarını günlük işlerle monotonlaştırır ve bir süre sonra kendilerini umutsuz, işe yaramaz "asalak bir varlık" olarak görür (De Beauvoir 1970: 65).

Susan da evin içinde kendi tanımı ile ekonomik olarak kocasına bağlı, her türlü özgürlüğü kısıtlanmış bir "mahkûm" (s. 487) olarak tanımlar. Zamanla, yalnız kalmak adına çatı katındaki boş odayı "Anne 
Odası" yapar, ancak kendini orada da kafese girmiş bir kuş gibi hisseder. Evin bahçesinde bir yabancının dolaştı̆̆ını düşünen ve hayaller görmeye başlayan Susan, korkularını eşi ile paylaşamaz. Kariyerini terk edip sadece anne ve eş olarak kendine yüklenen rollerin ağırlığında ezilen Lessing’in kahramanı, pişmanlık, hayal kırıklıkları ve öfke ile yoğrulur. Aynı zamanda, kocası Matthew’un, işe yakın olduğu gerekçesiyle hafta içi kaldığı şehirdeki dairesi bir garsoniyere dönüşmüş ve evlilikleri çatırdamaya başlamıştır. Üstelik eşinin, Myra Jenkins ile ilişkisini öğrenen Susan için ruhsal bunalımlar ve halüsinasyonlar artar. Evinin bahçesinde "kızll saçlı enerjik erkek" (s. 492), "şeytan" ve ya "düşman" olarak gördüğü bu hayal, onu deliliğge sürükler. "Hiçbir şey" (s. 504) yapmadığı ve sadece kendini dinlediği bir otel odası kiralar, huzuru bulur, ancak sonunda bu odada intihar eder: "İblisler orada değildi. Sonsuza dek gitmişlerdi, zira kadın özgürlüğünü onlardan satın alıyordu” (s. 516).

Batı edebiyatında 19. yüzyılda işlenen kadının benlik savaşı konusu, Osmanlı'da batılılaşma, kadın hareketleri ve savaştan dolayı kadının kamusal alanda daha çok yer alması ile başlar. Modern dünyanın gelişimi sayesinde, yeni haklar kazanan Osmanlı kadını, batılılaşmanın etkisi ile toplumda farklı rollere bürünmüştür. Hem sosyal hayata giren hem de eski rollerini koruması beklenen kadınların en büyük çelişkisinin sebebi yine ataerkil toplumun beklentileri olmuştur:

\begin{abstract}
Osmanlı erkeğinin eğitip kölelikten kurtararak özgürleştirdiği kadını (tıpkı kölesini eğitip azat eden köle sahibi gibi) kendine eş yapmasının temel konu edinildiğini belirtir. Erkek kahramanlar, kadınları kurtarıcı bu tavırları karşılığında, kendi kafasına uygun olarak ideal kadın-eş yaparken, erkeğe tüm varlığı ile bağlı, sadık ve minnettar olmalarını arzulamışlar (dır) (Sancar 2012: 129).
\end{abstract}

Türk kadının değişimini en güzel yansıtan Cumhuriyet Dönemi Türk Edebiyatı aydın kadınlarımızdan biridir Halide Edip Adıvar (1882-1964). İdeal kadının eğitimli, sosyal hayatta etkin ve vatan meselelerinden haberdar olması gerektiğini savunan Adıvar, eserlerinde başkahraman olarak "yeni kadın" figürleri seçmiştir: "Halide Edip, bütün kıymetlerde olduğu gibi, kadını da doğu ile batı, eski ile yeni, ruh ve beden arasında bir sentez halinde göstermekten yanadır” (Bekiroğlu 1999: 62).

İngiliz filoloji kürsüsünün öncülerinden biri olan Adıvar, öğrencisi Vahit Turhan ile "İstanbul Üniversitesi İngiliz Edebiyatı Semineri” için 1941 yllında Hamlet oyununu çevirmiş ve bu eseri Türk okuyucusuna tanıtmıştır (Araboğlu 2019: 990). Bu bağlamda, oyunu içselleştiren ve Türk okuyucusu için yorumlayan Halide Edip Adıvar'ın, bazı eserlerinde batı edebiyatı etkisi yoğun bir şekilde görülmektedir.

İkinci Meşrutiyet dönemi ile başlayan kadın hareketleri sayesinde Türk kadını, okuyan, sorgulayan ve düşünen bireyler olarak evlerinden çıkmış ve sosyal hayata adım atmışlardır: "Kadınların büyük işlere karışmaz anlayışı artık geride kalmıştır. Milletin kadınları ilk defa milletin hakiki anası ve efradı gibi bu felakete çare bulmak için bir araya toplanıyor" (Çalışlar 2010: 108). Savaş dönemindeki cepheyi tasvir eden Adıvar, aynı dönemlerde sosyal hayattaki bir başka savaşı da betimlemiştir: kadınların var olma savaşı.

Kadınların "benlik" arayışı konusunu içeren en çarpıcı Adıvar romanı Handan (1912), Abdülhamid'in İstibdat döneminde bir kadının toplumsal statüsünü ve psikolojik değişimlerini yansıtır. İlk olarak Tanin'de yayınlanan bu romanın ana temasını, Handan'ın aklı ve duyguları arasındaki mücadelesi oluşturur. Ağırlıklı olarak Refik Cemal'in mektupları bulunsa da Hüsnü Paşa, Handan ve diğer karakterlerin mektupları da romanın alt yapısındadır. Eğitimli ve entelektüel bir kadın olan Handan, "Cemal Bey'in alafranga" (s. 11) kızlarından biridir. Refik Cemal, onları "serbest tavırları ve hızlı İngilizceleriyle" (s. 11) yenidünya kızı olarak tanımlar. Sosyal ortamlarda başka kadınların "uykusunu 
getiren içtimaiyat, iktisat, felsefe ve hatta politika" (s. 42) konularında tartışmalara hararetle katılan Handan, birçok erkeğin hem ilgisini çeker hem de eleştirilere maruz kalır. Hocası Nazım'ın da ilgisini çeken Handan, onun beraberliklerine siyasi proje gözüyle baktığını düşünüp, evlilik teklifini geri çevirir: "Beni maksadıyla evlendiriyordu, beni kendiyle değil" (s. 80).

Handan, hayatı Avrupa'da geçmiş, entelektüel ve soğuk Hüsnü Paşa ile mantık evliliği yapar ancak bu evlilik ona sadece mutsuzluk getirir. Çelişkilerle dolu ve Hüsnü Paşa'nın "azap” (s. 142) olarak tanımladığı evliliğini bir türlü düzene sokamayan Handan, üzüntüden menenjit geçirir ve belleğini yitirmeye başlar. Kendisini aldatan ve mektuplarına cevap bile vermeyen kocasının ardından hastalanan Handan'a kuzeni Neriman'ın eşi Refik Cemal hastabakıcılık yapar. Londra'da beraber geçirdikleri zamanda Refik Cemal ve Handan birbirlerine âşık olur ancak bu yakınlıktan vicdan azabı duyan Handan romanın sonunda hayatını kaybeder.

Handan ve Susan farklı kültürlerin farklı kadın figürleridir ve dönemlerinin kadın benlik mücadelesini yansıtan en akılda kalıcı örneklerdir. Hem Shakespeare’in Ophelia'sını çağrıştıran hem de 20. yüzyıl 'yeni kadın figürü' olan bu iki kadın, bazı yönlerden birbirine benzer.

Ortak özelliklerden ilki, Susan ve Handan'ın, Ophelia gibi, ataerkil bir toplumda erkeklerin onlara dayattığı rollere uyum sağlayamamalarıdır. Ophelia, kendine biçilen kız çocuk, kız kardeş ve sevgili rollerine uyum sağlayamamış ve kaybolmuştur. Bu benlik kayboluşunun benzer örnekleri, yüzyllar sonra, Doris Lessing'in “Ondokuz Numaralı Oda” hikâyesindeki Susan ve Halide Edip Adıvar'ın Handan romanındaki Handan karakterlerinde karşımıza çıkar.

Kate Millett, Cinsel Politika (Sexual Politics) (1987) adlı kitabında, kadın erkek arasındaki ilişkiyi, ırklar, kastlar ve sınıflar arasındaki güç ilişkisine benzetir (45-47). Bu güç ilişkisinde, yüzyıllardır ataerkil toplumlarda, yazılı olmayan kanunlara göre, erkek dış dünyaya ait, aktif ve etkendir ancak kadın eve ait, pasif ve edilgendir. Erkekler tarih boyunca bu gücü ellerinde tutmuş ve toplumu şekillendirmiştir. De Beauvoir (1971), erkeklerin kadınları kendilerine bağlamak adına mitler geliştirdiklerini ve bu bağımlılığı, yasalar, din ve ya aile aracılığıyla yaptıklarını vurgular (169).

Evlenmeden ve anne olmadan önce ekonomik özgürlüğü olan Susan, ev hayatını seçip kendisini ailesine adamak zorunda kalan depresif bir kadındır. Betty Friedan Kadınlğın Gizemi (1983) kitabında kadınların toplumda verdiği kimlik savaşının nedenlerini şöyle sıralar: mutlu zannedilen ama gerçekte mutsuz olmaları, ev işlerinin altında ezilmeleri, kimlik bunalımı yaşamaları ve özgürlüklerini kaybettiklerinden dolayı çaresizlik hissetmeleri şeklinde açıklar. Aynı şekilde, Handan da romanın başında entelektüel ve politik konularda erkeklerle bile tartışan bir kadınken, evlendikten sonra Hüsnü Paşa'nın sessiz ve itaatkâr eşi olur çünkü bu dünya erkeklerin dünyasıdır ve dünyaya eleştirel açıdan bakması gereken erkeklerin karşısında kadınlar itaat eden varıklardır (De Beauvoir 1993: 11).

Her iki kadın da Ophelia gibi, duygularının göz ardı edilmesi ve toplumun beklentilerinin artması sonunda öznel bireyselliklerini yitirmişlerdir. Sevdiği adamın ondan uzaklaşması, babasının ölmesi ve abisinin yokluğu sonucu yalnız kalan Ophelia nasıl kaybolduysa, Susan ve Handan da kayıp bireylerdir. Susan, çocuklarının okula başlaması, eşinin işinden dolayı evden uzakta kalması ve hizmetkârla evde yalnız kalması sonucu ailesine yabancılaşır, delirir ve sonunda intihar eder. Handan ise, pişmanlıkları ve evliliğinden dolayı hayal kırıklıkları ile menenjit geçirir, hafızasını kaybeder ve romanın sonunda ölür. 
Bir başka ortak nokta ise, eserlerin başında, kadın karakterlerin düşünen, sorgulayan, zeki ve entelektüel bireyler olarak tanımlanmasıdır. Adıvar'ın romanındaki Handan da Susan gibi bilgiye "susamış bir dimağ” (s. 47) olarak tanımlanır. Sosyal ve politik meselelerle ilgilenen eğitimli Handan'ın bir amacı vardır: "Bu karanlık ve bedbaht memleketimin güzel insanlarının ruhuna akıtacağım ve ruhum bütün arzuları ve kabiliyetleri ile memlekete dökülecek” (s. 56).

Handan, batı kültüründen haberdar, dil bilen ve sorgulayan, tartışan Osmanlı’nın yeni kadın figürüdür. Romanda Neriman, Handan'ı şu şekilde tanımlanır:

Biz dört çocuk, hep aynı hocadan aynı tahsili görüyorduk, fakat Handan hepimizi arkada bıraktı. Bugün bizim tahsilimizi kazısan bir lisan, biraz da edebiyat bulursun. Fakat Handan öyle değildi. Onda öğrenmek bir ihtirastı. Bilmek, daima bilmek, yalnız kitaplardan değil, tabiatta, insanlarda her şeyi, görünmez şeyleri bilip anlamak için onda ebediyen susamış bir dimağ vardı (s. 47).

Ancak, romanın ortalarında Handan’ı Hüsnü Paşa ile sevgisiz bir evliliğin içinde buluruz. Susan’ın evliliği de "dengeli ve mantıklı" (s. 475) olarak tanımlanır. Handan da Susan da evlendikten sonra, sadık eş ve fedakâr anne rollerinden tatmin olamazlar ve eserlerin sonunda, güçlü kadın figürleri, pasif, acınası ve ruhen yaralı karakterler olarak karşımıza çıkar.

Ophelia'nın yaşadığı çelişkilerin sonucu olan delilik ve ya zihinsel çöküntü, Handan ve Susan için de bir başka ortak temadır. Aldatılan, kullanılan ve kandırılan Ophelia gibi, Susan ve Handan da ihanete uğrar. "Ondokuz Numaralı Oda” öyküsünde, Matthew, bir partide tanıştığı Myra Jenkins adlı genç bir kızla Susan'ı aldatmıştır. Susan bu ihaneti "anlayış" çerçevesinde kabul etse de "sindirilemeyecek bir şey" (s. 478) olarak tanımlar. Ancak, Susan aklı ve duyguları arasında yaşadığı çelişkide aklını seçer ve isyan etmez çünkü "Zekâ tartışmayı, somurtmayı, öfkeyi, içe kapanık sessizliklerini, suçlamaları ve gözyaşlarını yasaklar" (s. 480). Aynı şekilde, Handan da kocası Hüsnü Paşa'nın Matmazel Juliette ile ilişkisini öğrenir ve kocası metresiyle Medon'da gezerken, o köşesine çekilir ve sabırla bekler: "bir yeni metres daha dedim. Ve sabır değilse de metanetle beklemeye çalıştım” (s. 153).

Hayal kırıklıkları, çaresizlikleri ve depresyonları sonucu Handan ve Susan, etraflarındaki insanlardan uzaklaşmış ve toplumdan soyutlanmışlardır. Her ne kadar yalnızlığı tercih etse de, Susan, evde tek başına geçirdiği zamanlarda evliliğini, ailesini ve kimliğini sorgulamaya ve çelişkiler yaşamaya başlar: “...Susan neden (neyse ki her seferinde birkaç saniyeden uzun sürmediği halde) sanki hayatı bir çöl haline gelmiş, hiçbir şeyin önemi yokmuş ve çocukları kendisinin değilmiş gibi hissediyordu?” (s. 479).

Duyguları ve mantığı (ve ya ahlaki değerleri) arasında kalıp mantığını seçen ve topluma ayak uyduran Handan da, Susan gibi, etrafındakilerden uzaklaşmış ve yalnızlığa gömülmüştür. Duyarsız eşinin sebep olduğu hastalığından dolayı bir odada hapsedilen Handan, Refik Cemal hariç kimseyi göremez ve bu yalnızlık onu fiziksel ve ruhsal açıdan toplumdan uzaklaştırır.

Lessing ve Adıvar'ın eserlerindeki bir diğer ortak nokta ise, yüzyllar geçse bile, toplumun kadınlardan beklediği "namus, iffet" kavramlarıdır. 17. yüzyıldaki Ophelia'dan beklenen iffet, itaat ve sadakatin, 20. yüzyıldaki Susan ve Handan için de geçerli olduğunu görürüz. Handan, Refik Cemal'e olan aşkını kalbine gömer çünkü toplumun ondan beklentisi, Hüsnü Paşa istemese bile, evliliğine sahip çımasıdır çünkü Hüsnü Paşa'nın dediği gibi "bir kadının vücudu gibi ruhunun da kocasının sahası" (s. 150) olduğunu bilir. Handan, Türk toplumunun normları dışına çıkamaz ve aşkına rağmen eşine sadık kalır.

Susan da Handan gibi toplumun onlara dayattığı sorumlulukların farkındadır ve Matthew’un hatırlattı̆̆ gibi "ruhunun kendisine değil, ..., çocuklarına ait olduğunu" (s. 481) bilir. Susan da Handan gibi, 
toplumun onlardan beklediği sabır ve sadakat kavramlarına benliklerini kaybetme uğruna sahip çıkar. Aslında, affetmiş olsalar da, her ikisi de ihaneti kabul eden 'ruhsuz' kadınlara dönüşür ve öz benliklerini yitirirler çünkü toplum kadınlara bir başka rol daha yüklemiştir: ailenin birleştiricisi olmak.

Her iki karakter de öz benliklerini yitiren ve mutsuz olan kadınları simgeler. De Beauvoir, kadınların hikâyelerde ve masallarda bile ikinci sınıf olduğunu ve erkeklerin gölgesinde kaldığını (1971: 172-174) ve yüzyllardır "öteki varlık" (1971: 46) olduğunu söyler. Ona göre, kadınlar ancak, "başkaları için varlık" konumundan çıkıp "kendi için varlık" konumuna ulaştıklarında özgürleşebileceklerini savunur (Demir 1996: 84). Handan ve Susan, benliklerini kaybetmiş, toplumdan ve ailelerinden soyutlanmış ve ötekileştirilmişlerdir. De Beauvoir (1993), kadınların yabancılaşmasını, ev işleri yapmaya mahkûm edilmelerine ve hayatlarındaki kısır döngünün sebep olduğu mutsuzluğa bağlar (18).

Ayrı kültürler ve farklı dönemlerde resmedilen Handan ve Susan karakterleri, ortak noktaları bakımından okuyucuya, 17. yüzyılda betimlenen Ophelia'yı anımsatabilir. Bu üç kadın karakterin tek farkı kaderleridir. İntiharın dinsel açıdan günah kabul edildiği bir dönemde Shakespeare, Ophelia’nın intihar ettiğini açık bir şekilde söylemez. Neely (1991: 327), o dönemde kadınların intihar yolu olarak boğulma yöntemini tercih ettiğini ifade eder. Ancak, kraliçenin ve mezarcıların söylemlerinden onun canına bile isteye kıydığını çıkarabiliriz. Ölümünden sonra Ophelia'nın nasıl defnedileceğini tartışan Mezarcı "Bile bile canına kıymış bir kadın Hristiyan ölüsü gibi buraya mı gömülecek?” (s. 170) sorusu ile okuyucuyu aydınlatır. Ayrıca, ağıt yakan kraliçe Ophelia’nın ölümünü diğer karakterlere şöyle aktarır:

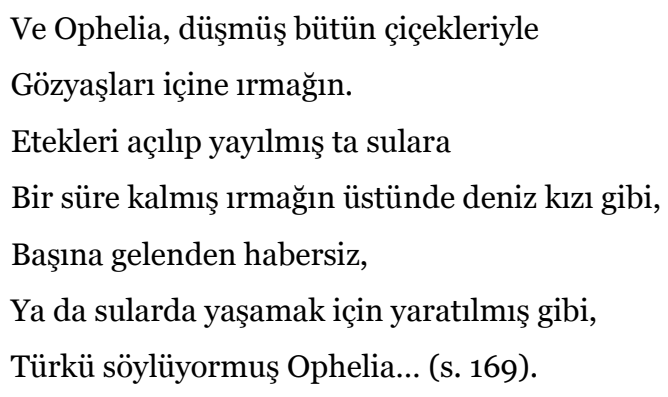

Susan da Ophelia gibi kendi olabilmek adına, başkalarının ona dayattığı seçenekler yerine kendi seçimini yaparak (Direk 2009: 32) bir otel odasında intihar eder. Onun intiharı, bir başkaldırı, isyan ve ya çı̆̆lıktır aslında:

Yeşil yatak örtüsüne sırtüstü uzandı, ama bacakları üşüyordu... Karanlık nehre doğru yavaşça ilerlerken orada yatmaktan, odaya, ciğerlerine, beynine dolan gazın hafif ve yumuşak tıslama sesini dinlemekten oldukça memnundu (s. 517).

Halide Edip Adıvar’ın Handan’ı ise intihar etmez ama ruhu ve beyni çoktan ölmüştür, hastalanır, hafızasını kaybeder ve kederinden eceliyle ölür.

\section{Sonuç}

Karşılaştırmalı Edebiyat bilimi sayesinde, okuyucu bir metnin başka bir metni çağrıştırmasını keşfeden, ortak ve ya farklı yönlerini bulan ve eserlerin derinine odaklanan aktif katılımcılar olurlar (Aktulum, 2000). Bu çalışma, 20. yüzyıl batı edebiyatından Doris Lessing’in Susan karakteri ve Türk edebiyatından Halide Edip Adıvar'ın Handan karakterinin, 17. yüzyıldaki W. Shakespeare'in unutulmaz çaresiz Ophelia’yı çağrıştırmasını kapsar. Araştırma sonucunda, dönemsel farklılıklara rağmen, ataerkil 
toplumlarda akıl ve duyguları arasında çelişkiler yaşayan kadınların "benlik savaşı" temasının dünya edebiyatlarında önemli bir ortak tema olduğu yargısına varılabilir.

Ataerkil toplumlarda kadınlar için biçilen rollere tepki gösteren, sorgulayan ve benlik arayışındaki kadınlar, yüzyllardır toplum tarafından dışlanmış, yalnızlığa mahkûm edilmiş, ruhsal ve zihinsel sorunlar yaşamış ve hatta hayatlarına son vermişlerdir. Ophelia, etrafındaki erkekler tarafından manipüle edilir, kullanılır ve çelişkiler arasında delirip intihar eder. Bu trajedi, okuyuculara, evliliğin yıprattığı Susan Rawlings ve çaresiz Handan'ı çağrıştırır. Üzerlerindeki baskıyı ve toplumsal beklentileri karşılayamayan birçok kadın gibi, bu çalışmadaki kadın karakterler de çaresizce benlik savaşı vermiş, kırılan onurlarının yükü ile ezilmiş, akıl ve duyguları arasındaki savaşı göreceli olarak kaybetmişlerdir. Aslında, onlar, sessiz çı̆̆lıkları ile sisteme isyan etmiş ve topluma uyum sağlamayı reddetmişlerdir. Susan'ın ailesinin ve toplumun baskısını "beynine basınç yapan bir el” (s. 488) olarak tanımlaması, Ophelia'nın delirmesi ve Handan'ın “dimağından hasta olması” (s. 165) kadınların yüzyıllardır ataerkil toplumların baskıları sonucu ruhsal ve zihinsel yıpranmalarına en güzel örneklerdir.

Kadınların merkezde olduğu edebi eserlerde asıl vurgulanan cinsel ayrımcılık ve ya eşitsizlik değil, benlik savaşıdır. Öznel varoluşlarını bulma ve koruma çabasında olan Susan ve Handan gibi kadın karakterler, hangi yüzyılda yaşamış olursa olsun benzer sebeplerden dolayı her dönemde edebi eserlerde yer bulurlar kendilerine. İyi yetişmiş, akıllı, eğitimli ve sosyal kadınların, dayatılmış geleneksel rollere isyanı, benlik arayışı, uyanışı ve toplum içinde çatışmalardan dolayı bocalaması, sadece yazıldıkları dönemlerde değil, günümüzde bile ataerkil toplumlardaki baskılar sonucu kadının iç dünyasındaki savaşın en önemli sebepleridir. Onların sessiz çı̆̆lıkları bazen intihar, bazen benlik kaybı bazen de delilik olarak karşımıza çıksa da, gerçeklik tanımının en güzel örnekleridir. Modern toplumun onlara kazandırdığı özgürlüklere rağmen, "mahkûm" (s. 487) olan kadınlar, her dönemde ve her kültürde toplumsal ve içsel çelişkiler sonucu birer Ophelia'dır.

\section{Kaynakça}

Adıvar, Halide Edip (2007). Handan. (21. b.). İstanbul: Can Sanat.

Aktulum, Kubilay (200o). Metinlerarası İlişkiler. İstanbul: Öteki.

Araboğlu, Aslı (2019). Halide Edip'in 'Hamlet'i: İngiliz Edebiyatı Seminer Mesaisinden Shakespeare Külliyatı. Gaziantep University Journal of Social Sciences 18 (3), 990-1003.

Aydın Kamil (2008). Karşılaştırmalı Edebiyat: Günümüz Post Modern Bağlamında Algılamışı. İstanbul: Birey.

Aytaç, Gürsel (2001). Karş̧laştırmalı Edebiyat Bilimi. Ankara: Kültür Bakanlığı.

Beauvoir, Simone De (1970). Kadın: Evlilik Çağı (Çev. B. Onaran). İstanbul: Payel. (Orijinal yayın tarihi, 1949)

Beauvoir, Simone De (1971). Kadın: Genç Kızlık Çağı (2). (Çev. B. Onaran). İstanbul: Payel. (Orijinal yayın tarihi, 1949)

Beauvoir, Simone De (1993). Kadın: Bağımsızlı̆̆a Doğru (Çev. B. Onaran). İstanbul: Payel. (Orijinal yayın tarihi, 1949)

Bekiroğlu, Nazan (1999). Halide Edip Adıvar. İstanbul: Şule Yayınları.

Birikiye, Selen Korad (2018). Kadınların Tarih Boyunca Suskunluğuna iki Örnek: Sessizlik ve Ophelia. Yaraticu Drama Dergisi 13(1), 37-52.

Carlisle, Carol J. (1967). Hamlet's Cruelty in the Nunnery Scene: The Actors' Views. Shakespeare Quarterly 18 (2), 129-140.

Çalışlar, İpek (2010). Halide Edip Biyografisine Sığmayan Kadın. İstanbul: Everest. 
Demir, Zekiye (1996). Modern ve post modern feminist akımlar (Yayınlanmamış yüksek lisans tezi). Kırıkkale Üniversitesi, Kırıkkale.

Direk, Zeynep (2009). Simone de Beauvoir: Abjeksiyon ve Eros Etiği. Cogito, 58, 11-39.

Friedan, Betty (1983). Kadınlı̆̆ın Gizemi (Çev. T. Mertoğlu). İstanbul: E. (Orijinal yayın tarihi, 1963)

Lessing, Doris (2015). 'Ondokuz Numaralı Oda'. (Çev. S. Yazıcıŏ̆lu). İstanbul: Can Sanat. (Orijinal yayın tarihi, 1963)

Millett, Kate (1987). Cinsel Politika. (Çev. S. Selvi). İstanbul: Payel. (Orijinal yayın tarihi, 1969)

Neely, Carol Thomas (1991). Documents in Madness: Reading Madness and Gender in Shakespeare's Tragedies and Early Modern Culture. Shakespeare Quarterly 42(3), 315-338.

Rousseau, Anthony ve Pichois, Claude (1994). Karşılaştırmalı Edebiyat. Çev. Mehmet Yazgan. Ankara: Milli Eğitim Bakanlığı.

Sancar, Serpil (2012). Türk Modernleşmesinin Cinsiyeti. İstanbul: İletişim (Orijinal yayın tarihi, 1983).

Shakespeare, William (1965). Hamlet. (Çev. S. Eyüboğlu). İstanbul: Remzi. (Orijinal yayın tarihi, 1609)

Tüzün, Hatice Övgü (2017). Representations of Lovesickness in Victorian Literature. SEFAD 38, 197210. 